\title{
Discovery of a New Self-incompatibility Allele in Apple
}

\author{
Shogo Matsumoto ${ }^{1}$ \\ Department of Biology, Faculty of Education, Gifu University, Gifu 501-1193, \\ Japan
}

\author{
Kentaro Kitahara \\ The United Graduate School of Agricultural Science, Gifu University, Gifu \\ 501-1193, Japan
}

Additional index words. Malus $\times$ domestica, Se-RNase, Se-allele, PCR

\begin{abstract}
A polymerase chain reaction (PCR)-based method for identifying the $S$-alleles in the Asian pear [Pyrus pyrifolia (Burm) Nak.] was applied to apple (Malus $\times$ domestica Borkh.) cultivars. With minor modifications in one of the primers, the fragments from $S$-genes (S-RNases) with introns were amplified from total DNA of apple cultivars possessing $S 2-, S 3-, S 5-, S 7-(=S d-), S 9$ - $(=S c$-), $S f$ - and $S g$-allele genotypes. $S$-genes within $S 24-(=S h$-) and $S 26$-alleles were also amplified. The PCR amplification step of this method appears to be useful for preliminary investigation of apple $S$-genotypes, especially for species or cultivars of unknown origin or history. Using the primers, which are a part of a new $S$-allele, the $S e$-allele encoding Se-RNase with an intron in the $S e$-allele was amplified. We cloned the cDNA of Se-RNase, and developed a PCR-restriction fragment length polymorphism (RFLP) analysis method for $S e$-allele identification. $S$-allele genotypes of seven apple cultivars were investigated.
\end{abstract}

Apple has gametophytic self-incompatibility (GSI) controlled by a single multiallelic $S$ locus. In this system, fertilization is inhibited when the pollen $S$-allele matches one of the pistil $S$-alleles. In GSI, both pollen and pistil are normal, but flowers can reject their own pollen (de Nettancourt, 1977).

The $S$-locus in apple has $S 2-(=S a-), S 3-$ (=Sb-), S5-, S7- (=Sd-), S9- (=Sc-), Sf-, Sg-, $S 24-(=S h-), S 26-$ and $S 27$-alleles. $S$-alleles encode S-RNases, many of which have been cloned (Broothaerts et al., 1995; Janssens et al. 1995; Kitahara et al. 1999, 2000; Sassa et al. 1996; Verdoodt et al., 1998). Based on the nucleotide sequences of the $S$-genes encoding S-RNases, a PCR-RFLP analysis method for $S$-allele identification has been developed (Janssens et al., 1995; Kitahara et al., 2000; Matsumoto et al., 1999a, b; Verdoodt et al., 1998). The method consists of PCR amplification of each $S$-gene using specific primers for individual $S$-genes, followed by digestion of the fragments by specific restriction enzymes.

\footnotetext{
Received for publication 3 Dec. 1999. Accepted for publication 17 Apr. 2000. We thank Junichi Soejima for supplying plant samples and Kaori Sugishita for her assistance. This research was supported by a Grant-in-Aid for Scientific Research from the Ministry of Education, Science, Sports, and Culture of Japan (No. 11660025). The cost of publishing this paper was defrayed in part by the payment of page charges. Under postal regulations, this paper therefore must be hereby marked advertisement solely to indicate this fact.

${ }^{1}$ To whom requests for reprints should be addressed Phone: +81-58-293-2257; fax: +81-58-293-2207; e-mail address: shmatsum@cc.gifu-u.ac.jp.
}

vestigated $S$-allele genotypes of seven apple cultivars.

\section{Materials and Methods}

Plant material. The Malus plants from collections at the Apple Research Center of the National Institute of Fruit Tree Science, Morioka, Japan, were used. Styles, together with the stigma, stamens, and petals of individual flowers of 'Delicious' were dissected at the popcorn stage, immediately frozen in liquid nitrogen, and stored at $-80{ }^{\circ} \mathrm{C}$. Young leaves were collected and stored at $-80{ }^{\circ} \mathrm{C}$ until analysis.

PCR amplification. Total DNA was isolated from leaves of individual plants as described by Thomas et al. (1993), and PCR was conducted using the sense ('FTQQYQ') and antisense ('anti-1/MIWPNV') primers (Table 1). Conditions for PCR were as described by Ishimizu et al. (1999). Amplified and digested fragments were separated on a $4 \%$ or $6 \%$ polyacrylamide gel in $40 \mathrm{~mm}$ Tris-acetate, $1 \mathrm{~mm}$ EDTA, $\mathrm{pH} 8.0$ (TAE) at $50-70 \mathrm{~V}$ for $1-1.5 \mathrm{~h}$.

Se-RNase cDNA cloning. Primers 'FTQQYQ' and 'anti-1/ ${ }_{M} I W P N V$,' amplified a 370 bp fragment in 'Delicious'. This fragment was directly sequenced by dideoxy chain termination on an ABI PRISM ${ }^{\mathrm{TM}} 377$ DNA sequencer (Perkin-Elmer Co., Urayasu, Chiba, Japan) using dRhodamine Terminator Cycle Sequencing Kits (Perkin-Elmer Co.). A primer 'PSNKNGP' (nucleotides 209-228 in Fig. 3) from the $370 \mathrm{bp}$ fragment (Table 1) was used as the gene-specific primer for rapid amplification of cDNA 3' ends (3' RACE) (Frohman et al., 1988).

Total RNAs from mature pistils of 'Delicious' were extracted essentially as described by Chang et al. (1993). Reverse transcription (RT) was performed in a total volume of $20 \mu \mathrm{L}$ containing $1 \mu \mathrm{L}$ (ca. $1.0 \mu \mathrm{g}$ ) of RNA, $0.125 \mu \mathrm{M}$ Oligo dT-Adaptor Primer (Takara Shuzo Co., Kusatsu, Shiga, Japan), 0.25 U AMV Reverse Transcriptase XL (Takara Shuzo Co.), 20 U RNase Inhibitor (Takara Shuzo Co.), $1 \mathrm{~mm}$ dNTPs, $5 \mathrm{~mm} \mathrm{MgCl}_{2}$ and 1x RNA PCR buffer (10 mm Tris- $\mathrm{HCl}, \mathrm{pH} 8.3,50 \mathrm{~mm} \mathrm{KCl}$ ). The analysis was programmed in a thermal cycler (GeneAmp 2400 apparatus; Perkin-ElmerCo.) and conducted under the following conditions: $60 \mathrm{~min}$ at $42{ }^{\circ} \mathrm{C}, 5 \mathrm{~min}$ at $99^{\circ} \mathrm{C}$, and cooling to $4{ }^{\circ} \mathrm{C}$.

Primers 'PSNKNPG' and M13 Primer M4 (Takara Shuzo Co.), a primer complementary to the adaptor region of the oligo dTAdaptor primer, were used for $3^{\prime}$ RACE. PCR was carried out in a total volume of $100 \mu \mathrm{L}$ containing $20 \mu \mathrm{L}$ of the RT reaction mixture,

Table 1. Primers cited in this manuscript.

\begin{tabular}{lll}
\hline \hline Primer name & Primer sequence $\left(5^{\prime}-3^{\prime}\right)$ & Reference \\
\hline FTQQYQ & TTTACGCAGCAATATCAG & Ishimizu et al., 1999 \\
anti-1/ ${ }_{\mathrm{M}}$ IWPNV & ACGTTCGGCCAAAT $/{ }_{\mathrm{C}}$ ATT & This paper \\
PSNKNGP & CCTTCAAACAAGAATGGACC & This paper \\
Sf-sense 2 & ATTAATCTGCCTCGCACTTG & Matsumoto et al, 1999b \\
Se-sense & AAACGTCTCTGCAATTCTCG & This paper \\
Se-antisense & ATCGTGATCCTTGTGGTGGT & This paper \\
anti-IIWPNV & AC $^{\mathrm{A}} /{ }_{\mathrm{G}}$ TTCGGCCAAATAATT & Ishimizu et al., 1999 \\
\hline
\end{tabular}


$0.2 \mu \mathrm{M}$ 'PSNKNPG' primer, $0.2 \mu \mathrm{M}$ M13 Primer M4, $2.5 \mathrm{~mm} \mathrm{MgCl}_{2}$, 1x RNA PCR buffer, and $2.5 \mathrm{U}$ Taq DNA polymerase (TaKaRa Taq ${ }^{\mathrm{TM}}$; Takara Shuzo Co.). The amplification program consisted of $2 \mathrm{~min}$ at $94^{\circ} \mathrm{C}$ for initial denaturation, 45 cycles of 30 s at $94{ }^{\circ} \mathrm{C}, 30 \mathrm{~s}$ at $60{ }^{\circ} \mathrm{C}, 1.5 \mathrm{~min}$ at $72^{\circ} \mathrm{C}$, and a final extension of $7 \mathrm{~min}$ at $72^{\circ} \mathrm{C}$.

Three cDNA $3^{\prime}$ end clones named Se $3^{\prime}-2$, Se $3^{\prime}-5$ and $\mathrm{Se}^{\prime}-8$ were obtained.

To obtain the $5^{\prime}$ ends of the cDNA $3^{\prime}$ end clones, PCR was conducted as described above using the primers 'Sf-sense 2' (Matsumoto et al., 1999b) and M13 Primer M4. Three cDNA clones, named Se5'-1, Se5'-6 and Se5'-9, corresponding to the cDNA 5' end clones, were obtained. PCR products were subcloned into the pCRII cloning vector. The nucleotide sequences of all the clones were determined as described above.

Se-allele specific PCR analysis. PCR was conducted using the 'Se-sense' (nucleotides 448-467 in Fig. 3) and 'Se-antisense' (nucleotides 655-674 in Fig. 3) primers (Table 1), for $S e$ allele identification. Each $35 \mu \mathrm{L}$ PCR mixture contained $1.0 \mu \mathrm{M}$ of each primer, 200 $\mu_{\mathrm{M}}$ deoxynucleotides, $10 \mathrm{~mm}$ Tris- $\mathrm{HCl}(\mathrm{pH}$ 8.3), $50 \mathrm{~mm} \mathrm{KCl}, 1.5 \mathrm{~mm} \mathrm{MgCl}_{2}, 0.001 \%$ (w/v) gelatin, $2.5 \mathrm{U}$ Taq polymerase, and 50 ng template DNA. Amplification was performed in a GeneAmp 2400 thermal cycler under the following conditions: 1) $3 \mathrm{~min}$ at $94{ }^{\circ} \mathrm{C}$ for denaturation; 2) $1 \mathrm{~min}$ at $94{ }^{\circ} \mathrm{C}$; 3) $1 \mathrm{~min}$ at $60^{\circ} \mathrm{C}$; and 4) $1 \mathrm{~min}$ at $72^{\circ} \mathrm{C}$ for 30 cycles, followed by a final extension for 10 $\min$ at $72{ }^{\circ} \mathrm{C}$. After PCR, the amplified fragments were digested by KpnI. Amplified and digested fragments were separated on a $4 \%$ polyacrylamide gel in TAE at $50-70 \mathrm{~V}$ for $1-1.5 \mathrm{~h}$.

\section{Results and Discussion}

The PCR-based method for identifying the $S$-alleles in the Asian pear was developed by Ishimizu et al. (1999). This method can be used with cultivars having two $S$-alleles, including a new $S$-allele, because the amino acid sequences 'FTQQYQ' and 'anti-IIWPNV', which are conserved among rosaceous $\mathrm{S}$ RNases, are used as the primers (Table 1). These sequences are well conserved not only in Asian pear but also in apple S-RNases. The nucleotide sequence of the $S 2$-allele encoding S2-RNase corresponding to one of the oligonucleotide primers, 'anti-IIWPNV,' shows mismatches at 2 positions (ACGTTTGGC CAAATCATT). We designed a new primer, 'anti-1/ ${ }_{\mathrm{M}} \mathrm{IWPNV}$ ' (Table 1), with one mismatch or none for all apple $S$-alleles, including the $S 2$-allele. From the length and sequence of apple $S$-alleles encoding $S$-RNases with introns, $349 \mathrm{bp}$ for $S 2$, ca. $1300 \mathrm{bp}$ for $S 3$ and $S 5$, 320 bp for $S 7,347$ bp for $S 9,538$ bp for $S f$ and $512 \mathrm{bp}$ for $S g$, should be amplified by the primers 'FTQQYQ' and 'anti-1/ ${ }_{\mathrm{M}} \mathrm{IWPNV}$ ' (Table 1). As shown in Fig. 1A, bands were amplified from 'Golden Delicious' (S2S3), 'Sansa' (S5S7), 'Fuji' (S9Sf) and 'Meku 10' $(\mathrm{S} 3 \mathrm{Sg}$ ). Bands of ca. $350 \mathrm{bp}$ and ca. $540 \mathrm{bp}$ were amplified from 'Baskatong' (S26S27) and 'Worcester Pearmain' ( $S 2 S h)$, respectively (Fig. 1A). The length and sequence of the introns of the $S h$-, S26- and $S 27$ - alleles are unknown. To confirm that the bands were from the $S$-alleles encoding S-RNases, they were digested by restriction enzymes. From the sequence data of coding regions of the $S$-alleles, a 55 bp fragment should be observed in $S h$ and $S 27$, but not $S 2$ and $S 26$, by BamHI digestion. However, a $153 \mathrm{bp}$ fragment should be observed at $S 26$, but not $S 27$, by $N d e$ I digestion. A fragment close to 55 bp was detected from 'Worcester Pearmain' $(S 2 S h)$, and a fragment close to $153 \mathrm{bp}$ was detected from 'Baskatong' (S26S27), suggesting that the $S h$ - and S26-allele were amplified by the primers (Fig. 1B). From the lengths of the amplified fragments, nine $S$-alleles were divided into five groups; $347-350 \mathrm{bp}$ of $S 2, S 9$ and $S 26$, ca. 1300 bp of $S 3$ and $S 5$, ca. 320 bp of $S d, 538-540$ bp of $S f$ and $S h$, and 512 bp of $S g$.

As all known $S$-alleles except the $S 27$ allele in apple were amplified by the primers, we tried to amplify the unknown $S$-alleles encoding S-RNases within 'Delicious', 'McIntosh' and 'Vista Bella'. The $S$-alleles in 'McIntosh' are unknown, and one of the $S$-alleles in 'Vista Bella' and 'Delicious' is known. Although no clear specific bands were obtained from 'McIntosh' and 'Vista Bella' except for a $540 \mathrm{bp}$ fragment from the $S h$-allele in 'Vista Bella,' a 370 bp fragment, which does not correspond to any apple $S$-alleles, was detected in 'Delicious' (Fig. 2), its progeny Orei' ('Golden Delicious' S2S3 x 'Delicious'), and its sport 'Starking Delicious', but was not detected in other $S$-genotype cultivars, suggesting that it was from an unknown $S$-allele within 'Delicious' (Fig. 1, 2). Previously, we identified the $S$-allele genotype of 'Delicious' as $S 9$ by the PCR-RFLP method (Matsumoto et al., 1999a). Thus, its $S$-genotype appears to be $S 9 S 9$ or a combination of $S 9$ and an unknown $S$-allele. Since no $S 9$-allele of 'Orei' was identified by $S$-allele-specific PCR-RFLP analysis (data not shown), the $S$-allele of 'Delicious' must be a combination of $S 9$ and an unknown $S$-allele. As the $S$-allele genotype of 'Delicious' was identified as $S c(=S 9) S e$ through pollination and progeny analyses
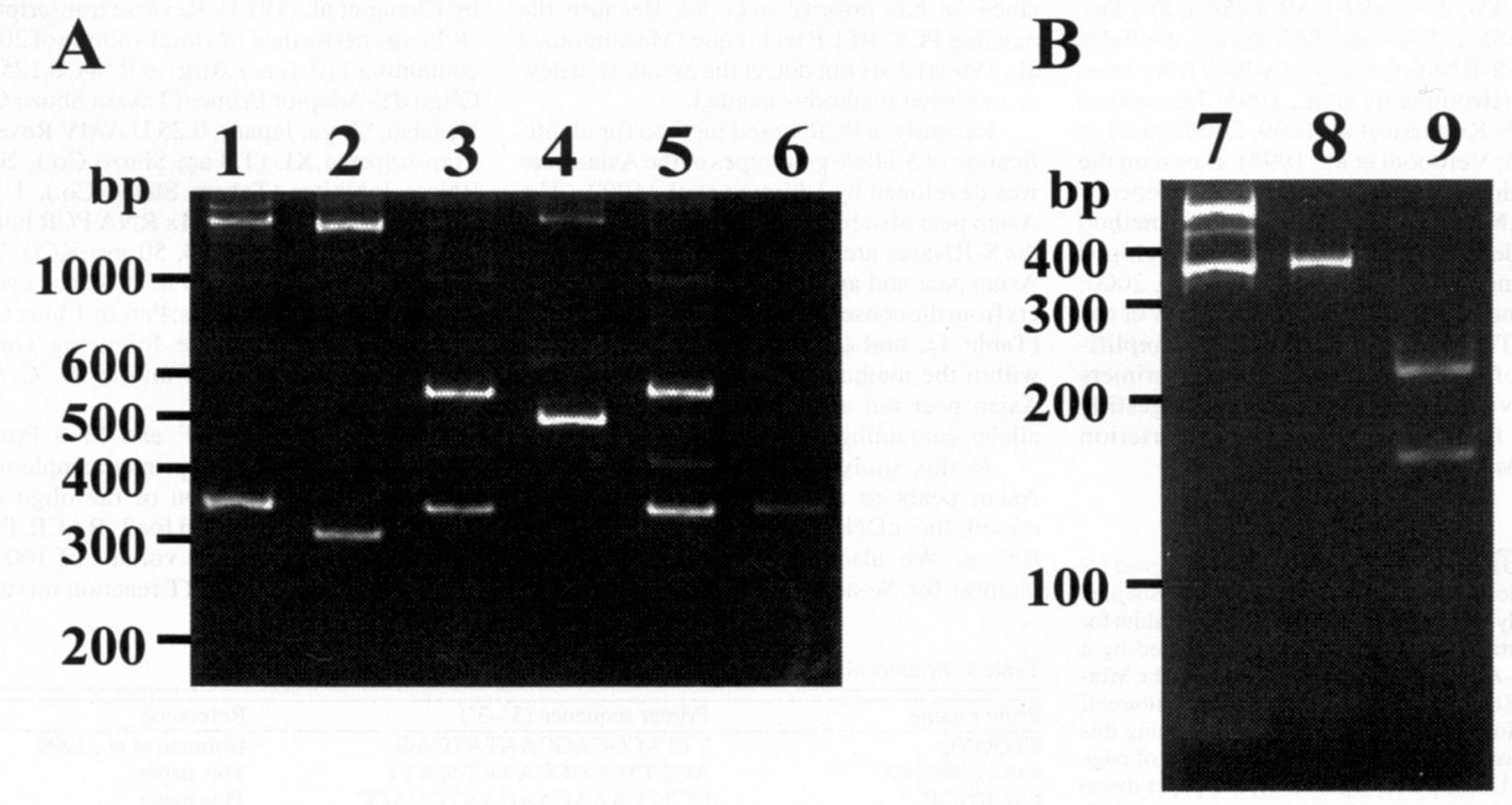

Fig. 1. Analysis of PCR fragments from six S-genotype-known apple cultivars: (A) Golden Delicious (S2S3) (lane 1), Sansa (S5S7) (lane 2), Fuji (S9Sf) (lane 3), Meku 10 (S3Sg) (lane 4), Worcester Pearmain (S2Sh) (lane 5), and Baskatong (S26S27) (lane 6). Analyses of the PCR fragment digests with restriction endonucleases: (B) BamHI digestion of the fragment of lane $5 \mathrm{in} \mathrm{Fig.} \mathrm{1A(lane} \mathrm{7),} \mathrm{BamHI} \mathrm{digestion} \mathrm{of} \mathrm{the} \mathrm{fragment} \mathrm{of} \mathrm{lane} 6$ in Fig. $1 \mathrm{~A}$ (lane 8), and NdeI digestion of the fragment of lane 6 in Fig. 1A (lane 9). 


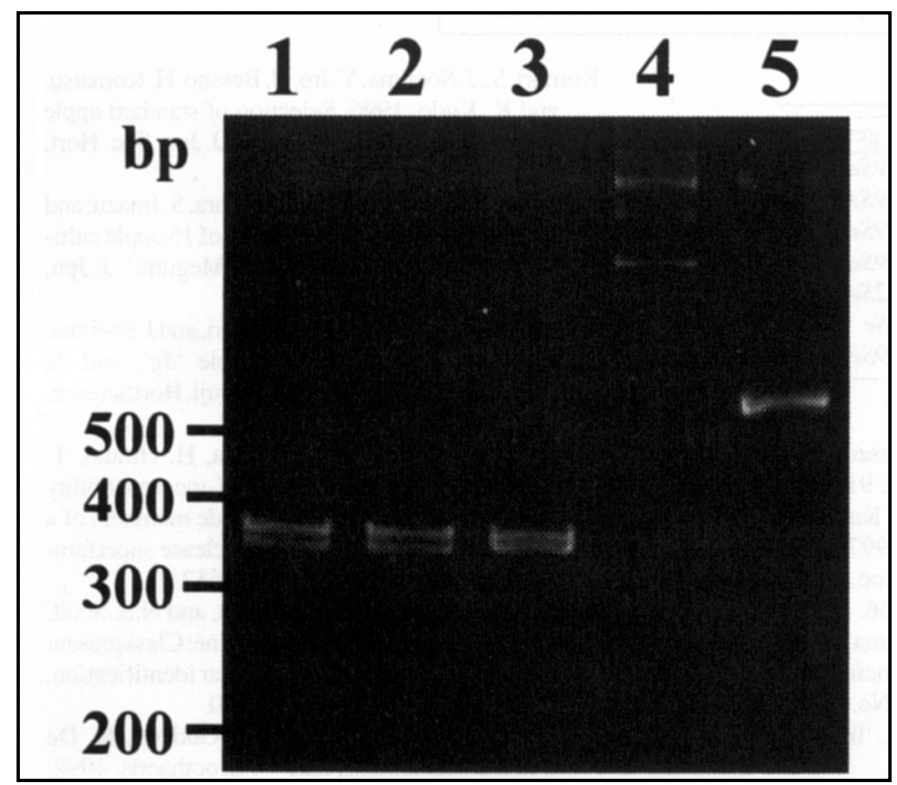

Fig. 2. Analysis of PCR fragments from five apple cultivars possessing unknown S-RNases: 'Delicious' (lane 1), 'Starking Delicious' (lane 2), 'Orei' (lane 3), 'McIntosh' (lane 4), and 'Vista Bella' (lane 5).
AACAAATTAATATTATTCAATGGGAATTACGGGGATGATATATATGTTTACAATGGTATT

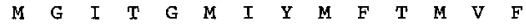
$S$ I I V I I I D $Y$ F $Q$ O 0 作 $\begin{array}{lllllllllllllllllllll}Q & Q & Y & Q & P & A & V & C & N & S & N & P & T & P & C & N & D & P & P & E & 54\end{array}$ AAAATTGITIACGGTTCACGGTTTGTGGCCTTCAAACAAGAATGGACCTGACCCAGAAAA 240 $\begin{array}{llllllllllllllllllllll}\text { K } & \text { L } & \text { F } & \text { T } & \text { V } & \text { H } & \text { G } & \text { L } & \text { W } & \text { P } & \text { S } & \text { N } & \text { K } & \text { N } & \text { G } & \text { P } & \text { D } & \text { P } & \text { E } & \text { K } & 74\end{array}$ ATGCAAGAATATACAAATGAATTCTCAGAAGATAGGAAATATGGCAGCCCAGTTGGAAAT 300 $\begin{array}{lllllllllllllllllllll}C & K & N & I & Q & M & N & S & Q & K & I & G & N & M & A & A & Q & \text { L } & E & \text { I } & 94\end{array}$ TATTTGGCCGAACGTACTCAATCGAACTGATCATGTAGGCTTCTGGGAAAGAGAGTGGCT 360 $\begin{array}{lllllllllllllllllllll}I & W & P & N & V & \text { L } & \mathbb{N} & R & \text { T } & \text { D } & \text { H } & \text { V } & G & \text { F } & \text { W } & \text { E } & R & \text { E } & \text { W } & \text { L } & 114\end{array}$ CAAACATGGCACCTGCGGGTATCCCACAATAAGGGACGACATGCATTACTTAAAAACAGT 420 $\begin{array}{lllllllllllllllllllll}R & H & G & T & C & G & Y & P & T & I & R & D & D & M & B & Y & I & K & T & V & 134\end{array}$ ATCAAAATGTACATAACCCAGAAACAAAACGTCTCTGCAATOCTCGCAAAGGCGATGAT 130

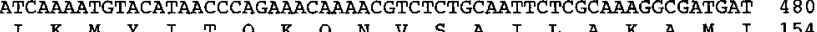

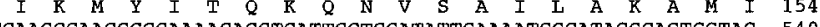
CAACCAACGGGAAAACAGGICATGGIGGAIAITGAAAAIGCCATACGCAGTGGTAC 540 $\begin{array}{lllllllllllllllllllll}Q & P & N & G & Q & N & R & S & L & V & D & I & E & N & A & I & R & S & G & T & 174\end{array}$ CAACAATATGAAACCAAAATTCAAGTGTCAAAAGAATACTAGGACAACGACGGAATTGGT 600 $\begin{array}{lllllllllllllllllllll}\mathbf{N} & \mathbf{N} & \mathbf{M} & \mathbf{K} & \mathbf{P} & \mathbf{K} & \mathbf{F} & \mathrm{K} & \mathbf{C} & \mathbf{Q} & \mathbf{K} & \mathbf{N} & \mathbf{T} & \mathrm{R} & \mathbf{T} & \mathbf{T} & \mathbf{T} & \mathbf{E} & \mathrm{L} & \mathrm{V} & 194\end{array}$ TGAGGTCACTCTTTGCCGTGATAGAGACTTAACGAAGTTCATAAATTGCCCCCAACCACC 660 $\begin{array}{lllllllllllllllllllll}E & V & T & L & C & R & D & R & D & L & T & K & F & I & N & C & P & Q & P & P & 214\end{array}$ ACAAGGATCACGATATCTCTGCCCCGCCGATGTTCAGTATTAATTAAGAGCGCGGCTAGC 720 $\begin{array}{lllllllllllllll}Q & G & S & R & Y & I & C & P & A & D & V & Q & Y & * & \\ \end{array}$ CACAAMTACACACACACACACACACACAMATATAMATAMAGTIGG TATICCATATATAGGACGAGATGAAGACACTTATGTGATTGTATTTCTAATGCATAAA 840

Fig. 3. Nucleotide and deduced amino acid sequences of the Se-RNase cDNA from 'Delicious' apple. Asterisk indicates stop codon. The site of the intron is shown by a triangle, and the sites of poly (A) additions by diamonds. The sequence of the Se-RNase cDNA was deposited under the DDBJ accession number $\mathrm{AB} 035273$
(Komori et al. 1996), we classified the unknown $S$-allele as $S e$-allele. To determine whether the $370 \mathrm{bp}$ band is a part of a Se-RNase or not, we determined its sequence directly. The deduced amino acid sequence of the fragment shows $65.7 \%$ to $77.6 \%$ similarities with other apple $S$-alleles encoding S-RNases, and contains the C2 domain 'LFTVHGLWP' at a corresponding site. Moreover, it contains an intron (169 bp) deduced from the presence of plant $5^{\prime}$ and $3^{\prime}$ splice-site consensus sequences, and is comparable in location to those of apple $S$-alleles.

The Se-RNase cDNA clones were obtained and sequenced based on the sequence data of the genomic DNA (Fig. 3). Nucleotides 116316 in Fig. 3 were completely matched with those of the $370 \mathrm{bp}$ genomic fragment except for a deduced intron sequence. The nucleotide sequences of the cDNA clones were the same except for the site of the poly(A) addition. The cDNA insert (878 bp) contains $681 \mathrm{bp}$ of coding region encoding 227 amino acids. In apple, S2-, S3-, Sd-, S9-, Sf-, Sg-, Sh-, S24-, S26-, and S27-RNase each code for 226-228 amino acids. The putative initiation codon ATG at position 20-22 is preceded by a stop codon TAA at position $8-10$ in frame. The sequence surrounding the first ATG codon (ATTCAATG) was well-conserved in the cDNAs of the apple $S$-alleles. The termination codon TAA is present at positions 701703 , followed by the $3^{\prime}$ untranslated region, which does not seem to contain the consensus polyadenylation signal AATAAA. The signal is also absent in the $S 2-, S c-, S g-, S 7$ - and $S h$ alleles. The deduced amino acid sequences of Se-RNase showed a high similarity to Pyrus pyrifolia S1- and S4-RNase (86.0\% to $86.8 \%$ ), whereas the similarities ranged from $64.6 \%$ to $71.1 \%$ for S2-, S3-, S5-, Sd-, Se-, S9-, Sf-, Sg-, Sh-, S26- and S27-RNase in apple.

From the sequence data of the $\mathrm{Se}$-allele, we developed a method for its identification. For $S e$-allele identification, we designed specific

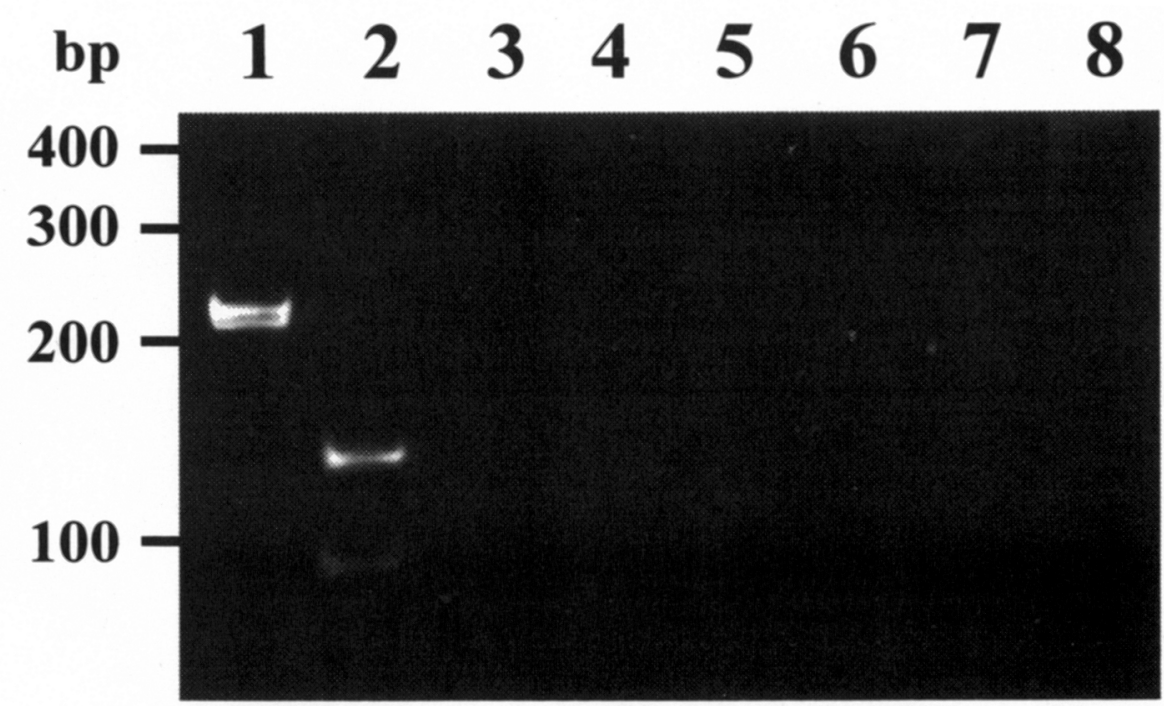

Fig. 4. Se-allele specific PCR-RFLP analysis. PCR products obtained by using 'Delicious' (lane 1), 'Golden Delicious' (S2S3) (lane 3), 'Sansa' (S5S7) (lane 4), 'Fuji' (S9Sf) (lane 5), 'Meku 10' (S3Sg) (lane 6), 'Worcester Pearmain' (S2Sh) (lane 7) and 'Baskatong' (S26S27) (lane 8) genomic DNA as templates, and 'Se-sense' and 'Se-antisense' primers. The product of lane 1 was digested by KpnI (lane 2).

primers 'Se-sense' and 'Se-antisense' (Table 1). We carried out PCR amplification, using 'Delicious' as a template. A PCR product very close to 227 bp was obtained (Fig. 4, lane 1). The fragment was specific for 'Delicious' and was not obtained from other $S$-genotype cultivars (Fig. 4, lane 3-8). In addition, the fragment was digested by KpnI(227 bp into 91 bp and $136 \mathrm{bp}$ ), which is a specific endonuclease for the PCR product of the Se-allele (Fig. 4, lane 2). Using this method, the Se-alleles of 'Holly,' 'Jonadel,' 'Melrose,' 'Orei,' 'Sekihikari' and 'Starking Delicious' were identified. We also identified the $S 2$ - and S9-allele of 'Holly,' 'Jonadel,' 'Melrose,' 'Orei' and 'Starking Delicious' using the
$S$-allele specific PCR-RFLP analysis method described by Matsumoto etal. (1999a, b) (Table $2)$. $S$-genotypes of seven apple cultivars possessing the $S e$-allele were identified (Table 2). All of the S-genotypes except for 'Sekihikari' are the expected ones based on their parental makeup.

\section{Literature Cited}

Broothaerts, W., G.A. Janssens, P. Proost, and W.F. Broekaert. 1995. cDNA cloning and molecular analysis of two self-incompatibility alleles from apple. Plant Mol. Biol. 27:499-511.

Chang, S., J. Puryear, and J. Cairney. 1993. A simple and efficient method for isolating RNA from pine trees. Plant Mol. Biol. Rpt. 11:113-116. 
Table 2. S-allele genotype of apple cultivars.

\begin{tabular}{lcc}
\hline \hline Cultivar & Parentage & $S$-allele genotype \\
\hline Delicious & & $S 9 S e$ \\
Holly & Jonathan $(S 7 S 9) \times$ Delicious & $S 9 S e$ \\
Jonadel & Jonathan $(S 7 S 9) \times$ Delicious & $S 9 S e$ \\
Melrose & Jonathan $(S 7 S 9) \times$ Delicious & $S 9 S e$ \\
Orei & Golden Delicious $(S 2 S 3) \times$ Delicious & $S 2 S e$ \\
Sekihikari & Indo $(S 7 S g) \times$ Richared Delicious & $S e$ \\
Starking Delicious & sport of Delicious & $S 9 S e$ \\
\hline
\end{tabular}

de Nettancourt, D. 1977. Incompatibility in Angiosperms, p. 28-57. In: R. Frankel, G.A.E. Gal, and H.F. Linskens (eds.). Monographs on theoretical and applied genetics. Springer-Verlag.

Frohman, M.A., M.K. Dush, and G.R. Martin. 1988. Rapid production of full-length cDNAs from rare transcripts: Amplification using a single genespecific oligonucleotide primer. Proc. Natl. Acad. Sci. U.S.A. 85:8998-9002.

Ishimizu, T., K. Inoue, M. Shimonaka, T. Saito, O. Terai, and S. Norioka. 1999. PCR-based method for identifying the $S$-genotypes of Asian pear cultivars. Theor. Appl. Genet. 98:961-967.

Janssens, G.A., I.J. Goderis, W.F. Broekaert, and W. Broothaerts. 1995. A molecularmethod for $S$-allele identification in apple based on allele-specific PCR. Theor. Appl. Genet. 91:691-698.

Katoh, N., K. Yamada, A. Kasai, M. Senda, K. Miyairi, and T. Okuno. 1997. cDNA cloning of apple S-RNase. Jpn. Soc. Biosci. Biotech. Agrochem. 71 (Suppl.):236.

Kitahara, K., H. Fukui, J. Soejima, and S. Matsumoto. 1999. Cloning and sequencing of a new $S$-gene 'Sg-RNase' (Accession No. AB019184) from Malus $\times$ domestica Borkh. 'Indo'. (PGR99-046) Plant Physiol. 119:1567.

Kitahara, K., J. Soejima, H. Komatsu, H. Fukui, and S. Matsumoto. 2000. Complete sequences of the $S$-genes, 'Sd-' and 'Sh-RNase' cDNA in apple. HortScience 35:712-715.
Komori, S., J. Soejima, Y. Ito, H. Bessho, H. Komatsu, and K. Kudo. 1996. Selection of standard apple varieties on S-allele genotypes. J. Jpn. Soc. Hort. Sci. 65 (Suppl.1):124-125.

Matsumoto, S., S. Komori, K. Kitahara, S. Imazu, and J. Soejima. 1999a. S-genotypes of 15 apple cultivars and self-compatibility of 'Megumi'. J. Jpn. Soc. Hort. Sci. 68:236-241.

Matsumoto, S., K. Kitahara, S. Komori, and J. Soejima. 1999b. A new $S$-allele in apple ' $S g$ ', and its similarity to the ' $S f$ ' allele from Fuji. HortScience. 34:708-710.

Sassa, H., T. Nishio, Y. Kowyama, H. Hirano, T. Koba, and H. Ikehashi. 1996. Self-incompatibility $(S)$ alleles of the Rosaceae encode members of a distinct class of the T2/S ribonuclease superfamily. Mol. Gen. Genet. 250:547-557.

Thomas, M., S. Matsumoto, P. Cain, and N.S. Scott. 1993. Repetitive DNA of grapevine: Class present and sequences suitable for cultivar identification. Theor. Appl. Genet. 86:173-180.

Verdoodt, L., A. Van Haute, I.J. Goderis, K. De Witte, J. Keulemans, and W. Broothaerts. 1998. Use of the multi-allelic self-incompatibility gene in apple to assess homozygocity in shoots obtained through haploid induction. Theor. Appl. Genet. 96:294-300. 